\title{
Agricultural production cooperatives, entrepreneurship and education in Iran
}

\author{
Tahmasb Maghsoudi ${ }^{1 \star}$, Hanieh Davodi ${ }^{2}$ and Masoud Hekmat ${ }^{1}$ \\ ${ }^{1}$ Department of Agricultural Management, Shoushtar Branch, Islamic Azad University, Iran. \\ ${ }^{2}$ Rural Development, Tehran University, Iran.
}

Accepted 5 January 2012

\begin{abstract}
Training is one of the components affecting the human resource development in a society. It is an effective component for developing entrepreneurship in agricultural production cooperatives. This study purpose is evaluating and classifying the needed trainings in agricultural production cooperatives to develop entrepreneurship. This study is descriptive and applicatory. Statistical population included 492 managing directors of active agricultural production cooperatives of Khuzestan province, of which 101 cooperatives were selected by sampling. Questionnaire was the data collection instrument, which its validity and reliability were proved using a panel of experts and Cornbach's alpha coefficient (0.82), respectively. Results show that five factors groups clarify about 83.99 of the training needed for the development of entrepreneurship in the Khuzestan agricultural cooperatives. These factors include Regulation training (23.42\%), risk management training (21.46\%), creativity training $(18.57 \%)$, marketing training $(12.83 \%)$, training for registering ideas, and moral ownership (7.68\%).
\end{abstract}

Key words: Training, entrepreneurship, agricultural production cooperative.

\section{INTRODUCTION}

Rapid growth of the world's population coupled with rising unemployment has contributed to a large gap among different income groups, and an increase in socioeconomic problems. Moreover, lack of business opportunities and insufficient income among rural areas have encouraged developing countries to consider new strategies such as creating job opportunities and enhancing rural livelihood. To meet this challenge, entrepreneurship strategy as a new paradigm has been proposed by many countries. This approach has also attracted numerous experts in diverse fields such as economics, sociology and psychology (Papzan et al., 2008).

Various studies have shown that one of the most important economical development objectives (whether in cities or villages) is employment, and most important mechanism and tool of it is the entrepreneurship.
Entrepreneurship reduces unemployment, increases the people's productivity, resource, and the community's income. Entrepreneurship requires a particular culture, which is very difficult to grow, and requires a long-term effort. Ability of understanding the changes and discovering the opportunities, participation and teamwork, creativity, spirit of independence and responsibility, risk and jeopardizing are all the constructive elements of this culture, which are not achieved by short-term, and task force plans. Best strategy for developing entrepreneurial culture in rural areas is improving entrepreneurial education through various promotional and training programs (Lashgarara et al., 2011).

Winn (1998) believes that entrepreneurship training brings up entrepreneurs by increasing knowledge about the labor market, increasing the psychological characteristics such as self-confidence, self-esteem, and 
self-efficacy. Jones and English (2004) in their studies found that there is a significant relationship between entrepreneurial training, self-confidence, and the skills of individuals in recognizing the business opportunities.

About the role and influence of training in the development, there are some necessary notes:

1. There is a mutual relationship between training and both society and entrepreneurship development. It means that training, in one hand, is the society's production and yield and, in the other hand and under special conditions, is the main factor of the social changes. From the economical -social development point of view, training is a historical subject related to the developments different strategies and its objectives, contents, methods, and scope are formed by the economical-social development and influence the development process.

2. Apart from other factors and with its important role in the development, entrepreneurship training cannot be so productive. Behavioral changes and evolutions resulted from training, however, can make areas and tendencies leading to the development objectives; but these changes can cause a real development when integrated and combined with non-educational inputs and factors (Jafarzadeh and Bazargan, 2005).

Entrepreneurship is a process of starting a creative venture by spending time, effort, and accepting and facing the risks like financial, psychic and social that result in the monetary as well as personal rewards. According to life cycle approach, entrepreneurial career has nine phases and business education is one of them. If the individual is getting education, encouraging decision making and skills building, then more entrepreneurial capabilities will be produced in individuals, provided such individuals enter family business in childhood (Sindhu et al., 2011).

Entrepreneurship in the 21st Century states that anyone wishing to become an entrepreneur must learn the following":

1) Identify opportunity: A business opportunity is defined as any venture that can bring a good return on investment within a reasonable period. In order to identify opportunity, created by changes in the environment, the entrepreneur must learn to be at alert and go out of his way to find out how his/her business is doing and how it could be improved upon.

2) Assemble required resources: It is one thing to identify an opportunity, but it is another thing to bring together the resources needed for the business to succeed. These resources include - people, capital, material and information. Of all these resources, the people are considered the most important.

3) Entrepreneurial management: With the opportunity identified and resources mobilized for implementation, the next task is how to manage the business. The choice of entrepreneurial management style in a small or medium scale enterprise is informed by increased international style of management that focuses on the pursuit of opportunities rather than on minimizing the use of existing asset or resources as in the conventional administrative management (Sotunde et al., 2011).

\section{Problem statement}

Based on the necessity of the move on commercial and competitive agriculture based market forces, Iranian farmers must work in a different form than previous one. So, one of the most important Iranian agricultures problems is that how the Iranian agriculture innovatively and creatively change from an "agricultural producer" to an "agricultural entrepreneur "so that it can identify the markets available opportunities and use it properly. Accordingly, what the Iranian agriculture needs is starting a difficult process of structural changes in this sector leading to have an active and effective agricultural market and develop the entrepreneurial activities in the agriculture sector.

Agricultural production cooperatives have capabilities for restructuring in Iran's agricultural sector. In Iran until 2010 , nearly 1,046 agricultural production cooperatives in the country's activities, that 4,963 villages have been covered and the number of members they have 278,362 people (Table 1).

Agricultural production cooperatives are one of the most rural organizations. The results show that the growth rate of production cooperatives in the decade before has increased. Performance and Acreage of major products has increased (Table 2). Therefore, the development of entrepreneurial activities in agricultural production cooperatives is important role in creating employment and production in rural areas.

Therefore, providing appropriate training to members of agricultural production cooperatives can be the starting point of the entrepreneurship development programs. This study purpose is identifying, classifying, and prioritizing the effective methods for entrepreneurship development training in Khuzestan's agricultural production cooperatives.

\section{MATERIAL AND METHODS}

This is an applied and non-experimental (descriptive) research. The methodology of this research is survey. Statistical population is 692 Director of agricultural production cooperatives, of which, according to Cochran formula, 101 were selected by proportional stratified sampling. Questionnaire was designed as the main tool of the study; these three parts are the managers personal and professional characteristics, cooperatives' features, and entrepreneurship development training. Sample selection, randomly from each region, was done by multi sectional stratified method suitable with the volume in Ahwaz, Dezful, Behbahan, Ramhormoz, and Abadan according to the geographical location of the city (north, south, east, and west); an appropriate number of managers 
Table 1. Status of agricultural production cooperatives in Iran.

\begin{tabular}{lcc}
\hline Status & $\mathbf{2 0 0 8}$ & $\mathbf{2 0 1 0}$ \\
\hline Cooperative & 1016 & 1046 \\
Rural coverage & 4872 & 4963 \\
Number of member & 272359 & 276362 \\
The amount of farmland(ha) & 2996219 & 3202791 \\
irrigated land & 1631231 & 1755448.5 \\
\hline
\end{tabular}

Source: agricultural ministry, 2010.

Table 2. Functional indices of agricultural production cooperatives in Iran.

\begin{tabular}{lcc}
\hline Product type & Cultivation (ha) & Yield (ton/ ha) \\
\hline Wheat & 640581 & 4.08 \\
Barley & 146183 & 3.43 \\
Corn & 71733 & 7.93 \\
Rice & 52387 & 4.61 \\
sugar beet & 152875 & 32.67 \\
Canola & 29202 & 2.08 \\
\hline
\end{tabular}

Source: agricultural ministry, 2010.

were selected from each city. For measuring the study tools, validity of the questionnaire used panel of experts, and a primarytest that involved completing 30 questionnaires for measuring reliability was done and the Cronbach alpha coefficient was $80 \%$. In this study, descriptive and inferential statistics were calculated and reviewed. The data were analyzed through SPSS version11.5 software.

\section{RESULTS}

\section{Personal characteristics}

Evaluating the personal characteristics showed, 92.1\% of. Respondents were male and $95 \%$ were married. Age evaluation of respondents also indicated that the average age was about 40.8 , which the most frequent ages were 30 to $40(55.4 \%)$. Respondents work record evaluation indicates that the average year of work in cooperatives is 8.24 years; the most frequent is below 5 years. The income average of respondents is 412.96 dollar monthly; the most frequent is below 400 dollar. The total income average of individuals is 495.46 dollar; the most frequents are 400 to 500 dollar (Table3).

\section{Cooperatives characteristics}

$80.2 \%$ of the studied cooperatives were Co-production of crops, 5.9\% Pisciculture cooperative, $4 \%$ were fattening cooperative, and $3 \%$ were distributing cooperative. A member evaluation indicated that the average number of cooperative members is 423, minimum 6 and maximum 2500 members; the most frequent numbers are 100 to $300(36.6 \%)$ (Table 4).

Cooperatives, according to the date of establishment, are classified into 4 classes. Most of them have been established from 1997 to 2006 (49.5\%) and only 11 cooperatives have been established during the last five years.

\section{Entrepreneurship training}

Results show that training the ways to use the bank facilities is the priority; further priorities are management skills and management training, familiarity with agriculture products insurance and its related regulations, knowing the business and traditional insurance, and training the skills for starting entrepreneurial businesses. Other priorities are familiarity with the laws and regulations of natural resources exploitation, being introduced to the concepts and methods of the general and partial planning in the production units, and the ICT roles and concepts in the cooperation sector (Table 5).

Factor analysis was used for evaluating the features influencing entrepreneurship development training in the agriculture production cooperatives in this regard and to determine the suitability of data for factor analysis, KMO coefficient and Bartlett test were used. Results show that the KMO coefficient was 0.825 and Bartlett test was significant so data was suitable.

Evaluation of the results indicate that there are five 
Table 3. Descriptive evaluation of the respondents' personal characteristics.

\begin{tabular}{|c|c|c|c|c|c|c|}
\hline Variable & & Frequency & Percent & Valid percent & Cumulative percent & Descriptive statistics \\
\hline \multirow{3}{*}{ Gender } & Male & 93 & 92.1 & 92.1 & - & Mode $=$ male \\
\hline & female & 8 & 7.9 & 7.9 & - & \\
\hline & Sum & 101 & 100 & 100 & & \\
\hline \multirow{5}{*}{ Age } & Below 30 & 7 & 6.9 & 6.9 & & Mean $=40.8$ \\
\hline & 30 to 40 & 56 & 55.4 & 55.4 & 6.9 & Mid=39 \\
\hline & 40 to 50 & 27 & 26.7 & 26.7 & 62.4 & S.D $=7.98$ \\
\hline & More than 50 & 11 & 10.9 & 10.9 & 89.1 & Min=28 \\
\hline & Sum & 101 & 100 & 100 & 100 & $\operatorname{Max}=60$ \\
\hline \multirow{6}{*}{ Experience } & Below 5 years & 48 & 47.5 & 49.5 & & Mean=8.24 \\
\hline & 5 to 10 & 25 & 24.8 & 25.8 & 49.5 & Mid=5.5 \\
\hline & 10 to 15 & 7 & 6.9 & 7.2 & 75.3 & S.D $=5.87$ \\
\hline & More than 15 & 17 & 16.8 & 17.5 & 82.5 & Min=2 \\
\hline & No answer & 4 & 4 & - & & $\operatorname{Max}=20$ \\
\hline & sum & 101 & 100 & 100 & 100 & \\
\hline \multirow{5}{*}{ Income from the cooperative } & Below 400 dollar & 35 & 34.7 & 59.3 & & Mean $=412.96$ \\
\hline & 400 to 500 dollar & 17 & 16.8 & 28.8 & 59.3 & Mid $=400$ \\
\hline & More than 500 dollar & 7 & 6.9 & 11.9 & 88.1 & S.D $=96.26$ \\
\hline & No answer & 42 & 41.6 & - & & Min=300 \\
\hline & sum & 101 & 100 & 100 & 100 & $\operatorname{Max}=600$ \\
\hline \multirow{6}{*}{ Income per month } & Below 400 dollar & 20 & 19.8 & 30.8 & 30.8 & Mean $=495.46$ \\
\hline & 400 to 500 dollar & 28 & 27.7 & 43.1 & 73.8 & Mid=450 \\
\hline & More than 500 & 17 & 16.8 & 62.2 & & S.D $=158.49$ \\
\hline & dollar & 36 & 35.6 & - & & Min=300 \\
\hline & No answer & & & & & $\operatorname{Max}=1000$ \\
\hline & sum & 101 & 100 & 100 & 100 & \\
\hline
\end{tabular}

factors determining about $83.99 \%$ of the variance related to factors influencing the entrepreneurship training in the agriculture production cooperatives of Khuzestan(Table 6).

The first factor named established cooperative Regulations training with a 5.62 Eigen value, which points up about $23.42 \%$ of the effective factors. This factor points out that instructing the regulations of cooperative legal, Rules and standards of export, Familiarity with laws and regulations of natural resources exploitation, and the cooperatives' concepts are essential to develop the entrepreneurship in the agriculture production cooperatives. One of the barriers of entrepreneurship development is the members and managers' lack of knowledge about the regulations of cooperatives, entrepreneurship, and supports so training programs should be planned 
Table 4. Descriptive evaluation of cooperatives characteristics.

\begin{tabular}{|c|c|c|c|c|c|c|}
\hline Variable & & Frequency & Percent & Valid percent & Cumulative percent & Descriptive statistics \\
\hline \multirow{8}{*}{ Kind of cooperative } & Co-production of crops & 81 & 80.2 & 80.6 & - & \multirow{8}{*}{ Mode $=$ Co-production of crops } \\
\hline & Service cooperative & 4 & 4 & 4.2 & - & \\
\hline & Fattening cooperative & 3 & 3 & 3.2 & - & \\
\hline & Pisciculture cooperative & 6 & 5.9 & 6 & - & \\
\hline & Rural cooperative & 1 & 1 & 1.1 & - & \\
\hline & Distributive cooperative & 4 & 4 & 1.5 & - & \\
\hline & No answer & 2 & 2 & - & - & \\
\hline & Sum & 101 & 100 & 100 & - & \\
\hline \multirow{6}{*}{ Number of members } & Below 100 & 36 & 35.6 & 38.7 & & \multirow{6}{*}{$\begin{array}{c}\text { Mean }=423.66 \\
\text { Med }=157 \\
\text { S. } 24.5 \\
\text { Min }=6 D=7 \\
\text { Max }=2500\end{array}$} \\
\hline & 100 to 300 & 34 & 33.7 & 36.6 & 38.7 & \\
\hline & 300 to 500 & 7 & 6.9 & 7.5 & 75.3 & \\
\hline & More than 500 & 16 & 15.8 & 17.2 & 82.8 & \\
\hline & No answer & 8 & 7.9 & - & & \\
\hline & Sum & 101 & 100 & 100 & 100 & \\
\hline \multirow{6}{*}{ Year of establishment } & Before 1979 & 18 & 17.8 & 19.4 & & \\
\hline & 1980 to 1996 & 18 & 17.8 & 19.4 & 19.4 & \\
\hline & 1997 to 2006 & 46 & 45.5 & 49.5 & 38.7 & \\
\hline & After 2006 & 11 & 10.9 & 11.8 & 88.2 & \\
\hline & No answer & 8 & 7.9 & - & & \\
\hline & Sum & 101 & 100 & 100 & 100 & \\
\hline
\end{tabular}

to explain these regulations.

The second factor entitled risk management training determines $21.46 \%$ of the effective factors with a 5.15 Eigen value. Therefore, training the risk management, production insurance, variety of business insurance, and risk management concepts and strategies is essential so that production cooperatives, more easily, would accept and produce their innovations.

The third factor named creativity training determines about $18.57 \%$ of the variance related to the factors. Lack of creativity in the agriculture production cooperative is one of barriers for the entrepreneurial development so training to develop creative ideas is necessary.

The fourth factor entitled marketing training determines about $12.83 \%$ of factors' variance. It points out the cooperatives' weakness in marketing the agricultural production which has weaken the financial foundation and the cooperatives' risk taking power .So, agricultural production marketing training is necessary.

The fifth factor named idea registration and intellectual property factor determines about $7.68 \%$ of the effective factor .It points out the problems related to the innovation and invention registration which the cooperatives are not familiar with. Therefore, knowing the invention registration process and the intellectual property are progressing factors for developing the entrepreneurship in cooperatives (Table 7).

\section{DISCUSSION AND SUGGESTION}

Although entrepreneurship in the agriculture 
Table 5. Respondent's distribution based on the entrepreneurship development training in cooperation.

\begin{tabular}{|c|c|c|c|c|}
\hline Items & Mean & Sd & CV & Rank \\
\hline Methods of using the bank facilities & 4.2 & 0.87 & 0.209 & 1 \\
\hline Management skills and entrepreneurial businesses training & 3.9 & 0.86 & 0.225 & 2 \\
\hline Familiarity with agricultural products insurance and related laws & 3.8 & 0.90 & 0.235 & 3 \\
\hline Familiarity with a variety of businesses and profession insurance & 3.7 & 0.90 & 0.241 & 4 \\
\hline Training skills for starting entrepreneurial businesses & 3.6 & 0.91 & 0.250 & 5 \\
\hline Training laws and standards of production and supply of products and services & 3.8 & 0.95 & 0.251 & 6 \\
\hline Introduction to the stock market of agricultural products & 3.5 & 0.88 & 0.253 & 7 \\
\hline Health and safety principles in production and supply products & 3.2 & 0.81 & 0.255 & 8 \\
\hline Training companies and economic institutions` legal issues & 3.7 & 0.98 & 0.256 & 9 \\
\hline Training concepts and principles of products marketing and market updating & 4 & 1.06 & 0.257 & 10 \\
\hline Familiarity with the concepts and types of budgeting methods and techniques & 3.4 & 0.97 & 0.258 & 11 \\
\hline Familiarity with international organizations and non-governmental organizations & 3.1 & 0.88 & 0.286 & 12 \\
\hline Network communication of producers and suppliers of products and services & 3.4 & 0.97 & 0.287 & 13 \\
\hline Rules and standards of export & 3.5 & 1.03 & 0.291 & 14 \\
\hline Problem finding and decision methods training & 3.8 & 1.1 & 0.293 & 15 \\
\hline Familiarity with technology producer enterprises & 3.2 & 0.96 & 0.303 & 16 \\
\hline Familiarity with the process of localization of research results & 3.3 & 1.01 & 0.306 & 17 \\
\hline Familiarity with the rights of producers, consumers and distributors of products & 3.3 & 1.02 & 0.307 & 18 \\
\hline Training the commissioning and management of company issues & 3.8 & 1.18 & 0.310 & 19 \\
\hline Familiarity with entrepreneurial educational organizations and counseling centers & 3.6 & 1.12 & 0.314 & 20 \\
\hline New economical concepts (globalization, international trade and ...) & 3.2 & 1.05 & 0.328 & 21 \\
\hline Principles, concepts , and strategies for risk management & 3.4 & 1.15 & 0.335 & 22 \\
\hline Creativity and innovation development training & 3.4 & 1.16 & 0.341 & 23 \\
\hline Familiarity with the concepts and principles of cooperation and cooperatives laws & 3.6 & 1.26 & 0.348 & 24.5 \\
\hline Familiarity with the concepts of project writing and business planning & 3.6 & 1.25 & 0.348 & 24.5 \\
\hline Familiarity with the rules of privatization & 3.5 & 1.22 & 0.360 & 26 \\
\hline Training the familiarity with various stages of private companies, cooperatives & 2.8 & 1.01 & 0.366 & 27 \\
\hline Familiarity with the hierarchy and structure of the ministry of cooperation & 3 & 1.13 & 0.374 & 28 \\
\hline Familiarity with the concepts and functions of ICT in the cooperative & 3.2 & 1.27 & 0.391 & 29 \\
\hline Familiarity with general and partial programming concepts and techniques & 3.2 & 1.26 & 0.393 & 30 \\
\hline Familiarity with laws and regulations of the exploitation of natural resources & 3.1 & 1.24 & 0.396 & 31 \\
\hline Familiarity with activities of research centers and institutions & 2.9 & 1.26 & 0.438 & 32 \\
\hline
\end{tabular}

Table 6. extracted factors with Eigen value, variance percent and cumulative variance percent.

\begin{tabular}{lccc}
\hline Factors 1 & Eigen value & Variance percent & Cumulative variance \\
\hline 1st & 5.62 & 23.42 & 23.42 \\
2nd & 5.15 & 21.46 & 44.89 \\
3rd & 4.45 & 18.57 & 63.47 \\
4th & 3.08 & 12.83 & 76.31 \\
5th & 1.84 & 7.68 & 83.99 \\
\hline
\end{tabular}

production cooperative, according to its nature and basics, is not different from ones in the metropolitan areas or all other economical sectors, inputs needed for developing entrepreneurship such as capital, management, training, technology, institutions and organizations, transportation infrastructures, market accessibility, distribution network, and skilled labor, more effortlessly, can be found in the metropolitan areas. Therefore, as long as there is entrepreneurship development problems in the metropolitan areas, there is 
Table 7. Variables related to each coefficient, coefficient rate gained through rotational matrix.

\begin{tabular}{|c|c|c|}
\hline Factor & Items & Coefficient rate \\
\hline \multirow{4}{*}{ Established cooperative regulations training } & Training commissioning and managing a company's legal issues & 0.779 \\
\hline & Rules and standards of export & 0.682 \\
\hline & Familiarity with laws and regulations of natural resources`exploitation & 0.711 \\
\hline & Familiarity with the concepts and principles of cooperation and cooperatives' laws & 0.776 \\
\hline \multirow{5}{*}{ Risk management training } & Familiarity with agricultural products` insurance and related laws & 0.676 \\
\hline & Familiarity with a variety of professions and businesses`insurance & 0.721 \\
\hline & Principles, concepts and strategies for risk management & 0.825 \\
\hline & Network communication of producers and suppliers of products and services & 0.793 \\
\hline & Ways to use the banking facilities & 0.790 \\
\hline \multirow{3}{*}{ Creativity training } & Training the Problem finding and decision methods & 0.853 \\
\hline & Training ways for developing creativity and innovation & 0.733 \\
\hline & Training the Management skills and entrepreneurial businesses administration & 0.907 \\
\hline Marketing training & Training concepts and principles of products marketing and market updating & 0.815 \\
\hline idea registration and intellectual property & Training the familiarity with the idea registration process and intellectual property & 0.919 \\
\hline
\end{tabular}

more in the rural and agricultural ones.

It is clear that there are not enough supports and strategies for developing the cooperatives and entrepreneurship but, because of the lack of knowledge about these regulations and laws, agriculture production cooperatives were successful in the entrepreneurship development. It should be considered that entrepreneurship, through training, cannot be motivated rapidly in the agriculture production cooperatives and we have lost much time in this field. If, today, all conditions for the entrepreneurship development are ready, the effect would be appeared in a longterm period so, in short- term, activities to form appropriate structures for developing the entrepreneurship in the agriculture production cooperatives can be constructive. The results of this study are in accordance with the study results of Bahrami and Zamani (2006), Boroumandnasab (2002) and Karimi et al. (2006).

Agriculture production cooperatives have a weak economical basis which is related to the rural economical basis weakness. Therefore, farmers are weak in taking risks doubting them to face the innovation and, finally, they reject it. Training the Insurance regulation for entrepreneurial projects' investment, risk management strategies, banking and insurance networks for supporting the entrepreneurs in the production cooperatives, in a medium -term period, can solve some of the entrepreneurship development problems. The results of this study are in accordance with the study results of Jafarzadeh and Bazargan (2005), Papzan et al. (2008), Jelodar et al. (2007).
Other factors affecting the development of entrepreneurship training are marketing trainings, which, due to the weakness of the marketing system in agriculture products, need more attention. Marketing training should be in the fields of information and production statistics, supply, demand, exports, distribution channels, market research, and registration training in order to maintain the intellectual rights of people, since achieving these changes may need a long time.

In this regard, it is suggested that educational preparations adopted in training packages for entrepreneurial skills training to enhance directs agricultural cooperatives about these cases and the entrepreneurial skills training centers should be developed too. For training the directors, the 
required infrastructures should be strengthened to equip the entrepreneurial training centers. And government should investment in entrepreneurial training projects. Suggestions which prepared these changes to be observable in entrepreneurship training in agricultural production cooperatives are:

1. Designing appropriate policies and programs to develop the content, methods, and cooperation-learning environment in entrepreneurial training.

2. Designing programs to develop entrepreneurial skills and characteristics in the cooperatives educated members.

3. Creating the entrepreneurial culture in the cooperative environment by managing directors and board members.

4. Changing the members viewpoint from governmental support to the utilization of cooperatives ability to improve the life conditions.

5. Bilateral relationship between the university and research and cooperation; cooperation incubators configuration is suggested.

6. Moral and financial support for members by the cooperative to conduct and assess the projects innovatively and creatively.

7. Organizing workshops, festivals and seminars for entrepreneurs to be familiar with cooperatives entrepreneurship issues by the Ministry of Cooperation; it should be member centered, regional, and organized in the cities.

8. Publishing brochures, magazines, pamphlets, and videos about cooperatives entrepreneurship.

9. Entrepreneurship has both theoretical and practical dimensions. So, entrepreneurship training should cover the cognitive, emotional, and mental moving domains, and should not be limited to the cognitive domain.

10. Developing detailed research about the cooperatives entrepreneurship training and other related fields according to the conditions and requirements of Iran.

\section{REFERENCES}

Bahrami F, Zamani GH (2006). The required competencies for employment and its relation with job achievements. J. Jihad. 727: 67 78

Boroumandnasab M (2002). The relationship amongst economicsocial, achievement motivation, skill, creativity and self-esteem and entrepreneurship. Thesis of Shahid Chamran university.

Jafarzadeh M, Bazargan A (2005). Analysis of factors effective in entrepreneurship of the graduates of Tehran University. Cult. Manag. J. 2: 7.

Jelodar R, Farajollah Hosseini SJ, Mirdamadi SM (2007). Influencing factors on achievement of rural women entrepreneurship in North region. Q. Vil. Dev. 4: 87.

Jones C, English J (2004). Contemporary approach to entrepreneurship Education and Training. Karimi AR, Sedighi H, Feli S (2006). Electronic education: A new approach in education of rural women. The congress of women and internet.

Lashgarara F, Roshani N, Omidi Najafabadi M (2011). Influencing factors on ntrepreneurial skills of rural women in Ilam City, Iran. Afr. J. Bus. Manage. 5(14):5536-5540.

Agricultural ministry of Iran (2010). Status of agricultural production cooperatives and performance indicators. Available in http://www.maj.ir/portal/Home/Default.aspx

Papzan A, Zarafshani K, Tavakoli M, Papzan M (2008). Determining factors influencing rural entrepreneurs' success: A case study of Mahidasht township in Kerman shah province of Iran. Afr. J. Agric. Res. 3(9):597-600.

Sindhu A, Naeem H, Saif MI, Mehmood S (2011). Business education and entrepreneurial capabilities in Pakistan. Afri. J. Bus. Manag. $5(5): 1749-1754$

Sotunde OA, Obasan KA, Salako MA, Oni KA, Oduwole RA (2011). Training as a nexus for entrepreneurial emergence: An appraisal of OGEGEP trainees experience in Ogun State, Nigeria. Afr. J. Bus. Manage. 5(5):1958-1962.

Winn J (1998). Assessing the environment: Conditions for female entrepreneurship. J. Bus. Venture. 